\title{
EFFECT OF ANNEALING ON THE REAL STRUCTURE AND MICROSTRUCTURE OF ADVANCED LASER PROCESSED AISI H13 TOOL STEEL
}

\author{
Karel Trojan $^{a, *}$, VÁclav Ocelík $^{b}$, Nikolaj GaneV ${ }^{a}$, \\ StANislaV NĚMEČEK ${ }^{c}$, JAROSlaV ČECH $^{d}$, JiŘí ČAPEK ${ }^{a}$, JAKUB NĚMEČEK ${ }^{a}$ \\ ${ }^{a}$ CTU in Prague, Department of Solid State Engineering, Faculty of Nuclear Sciences and Physical Engineering, \\ Trojanova 13, 12000 Prague 2, Czech Republic \\ ${ }^{b}$ Department of Applied Physics, Zernike Institute for Advanced Materials, Faculty of Science and Engineering, \\ University of Groningen, Nijenborgh 4, 9747 AG, Groningen, The Netherlands \\ ${ }^{c}$ RAPTECH s. r. o., U Vodárny 473, 33008 Zruč-Senec, Czech Republic \\ ${ }^{d}$ CTU in Prague, Department of Materials, Faculty of Nuclear Sciences and Physical Engineering, Trojanova 13, \\ 12000 Prague 2, Czech Republic \\ * corresponding author: Karel.Trojan@fjfi.cvut.cz
}

\begin{abstract}
The aim of this paper is to describe the effects of annealing on the microstructure of laser cladded AISI H13 tool steel using various methods. Advanced laser technology has the potential to replace conventional methods to make and repair dies. However, it has to be determined whether the newly created surface still needs to be heat-treated, which would cause additional repair costs. No significant effect of heat treatment on the microstructure and real structure of the clads was detected, but further confirmation, in particular by measuring wear resistance, is needed.
\end{abstract}

KEYWORDS: laser processing, cladding, annealing, microstructure, AISI H13 tool steel.

\section{INTRODUCTION}

Hot working tool steel AISI H13 is one of the most common die material used in metal and casting industries. Dies suffer damage due to wear and thermodynamic stresses during their lifetime [1]. Therefore, various methods have been developed for its repair. A great benefit of laser cladding in this field is a high productivity with minimal influence on surrounding material by thermal stresses due to low heat input 22. Therefore, the aim of this contribution is to describe the effects of annealing on the real structure and microstructure of laser cladded AISI H13 tool steel using X-ray diffraction (XRD) to determine real structure and residual stresses (RS), instrumented indentation (nanoindentation) technique and orientation imaging microscopy (OIM) based on electron backscatter diffraction (EBSD), and energy-dispersive X-ray spectroscopy (EDS). During the laser cladding, rapid cooling and thus the formation of brittle martensitic microstructure could occur [3]. Hence, it is important to observe the effect of annealing on the real structure and microstructure which subsequently influences the properties of the newly created surface of dies.

\section{EXPERIMENTAL}

Laser cladding was carried using a diode laser Laserline $5.5 \mathrm{~kW}$ with optical head Precitec Y52. Laser power density $140 \mathrm{~J} / \mathrm{mm}^{2}$ was applied to form a single clad with the length of $137 \mathrm{~mm}$, width of $6 \mathrm{~mm}$ and height of approx. $1 \mathrm{~mm}$ above substrate made from construction S355 steel. The powder of the AISI H13 tool steel was used with an average particles diameter of $53.1 \pm 15.9 \mathrm{\mu m}$. Three samples were made from the clad with average dimensions $15 \times 12 \times 5 \mathrm{~mm}^{3}$. The first sample from the clad was analysed without heat treatment. The second sample was annealed at $550{ }^{\circ} \mathrm{C}$ for 2 hours and the third sample was heat treated twice at the same temperature for 2 hours. SEM image of the cross-section of the single clad with used directions can be seen in Figure 1. Lack of the fusion on the sides of the clad could be observed, it is probably the result of improper setting of laser power density.

X-ray diffraction analysis was carried out using an $X$ 'Pert PRO MPD diffractometer with chromium tube anode and pinholes determining irradiated area of primary beam, with size of $1 \times 1 \mathrm{~mm}^{2}$ in longitudinal clad direction $\mathrm{L}$ and $2 \times 0.5 \mathrm{~mm}^{2}$ in transversal direction $\mathrm{T}$, respectively. Diffraction lines $\operatorname{Cr} K \alpha_{1}$ of the planes $\{211\}$ of the $\alpha$-Fe were fitted by Pearson VII function and Rachinger's method was used for separation of the diffraction lines $K \alpha_{1}$ and $K \alpha_{2}$. For residual stress evaluation, $\sin ^{2} \psi$ method and X-ray elastic constants $1 / 2 s_{2}=5.75 \mathrm{TPa}^{-1}, s_{1}=-1.25 \mathrm{TPa}^{-1}$ were used [4. $\mathrm{RS}$ were measured at the top of the clad from the upper side in two directions. Full widths of the measured diffraction lines $\operatorname{Cr} K \alpha_{1} K \alpha_{2}$ at half of the maximum were also evaluated for both directions. Full width at half of the maximum (FWHM) parameter depends on microstrains (fluctuation of inter-planar distances), crystallite size (size regions of coherent scattering) 


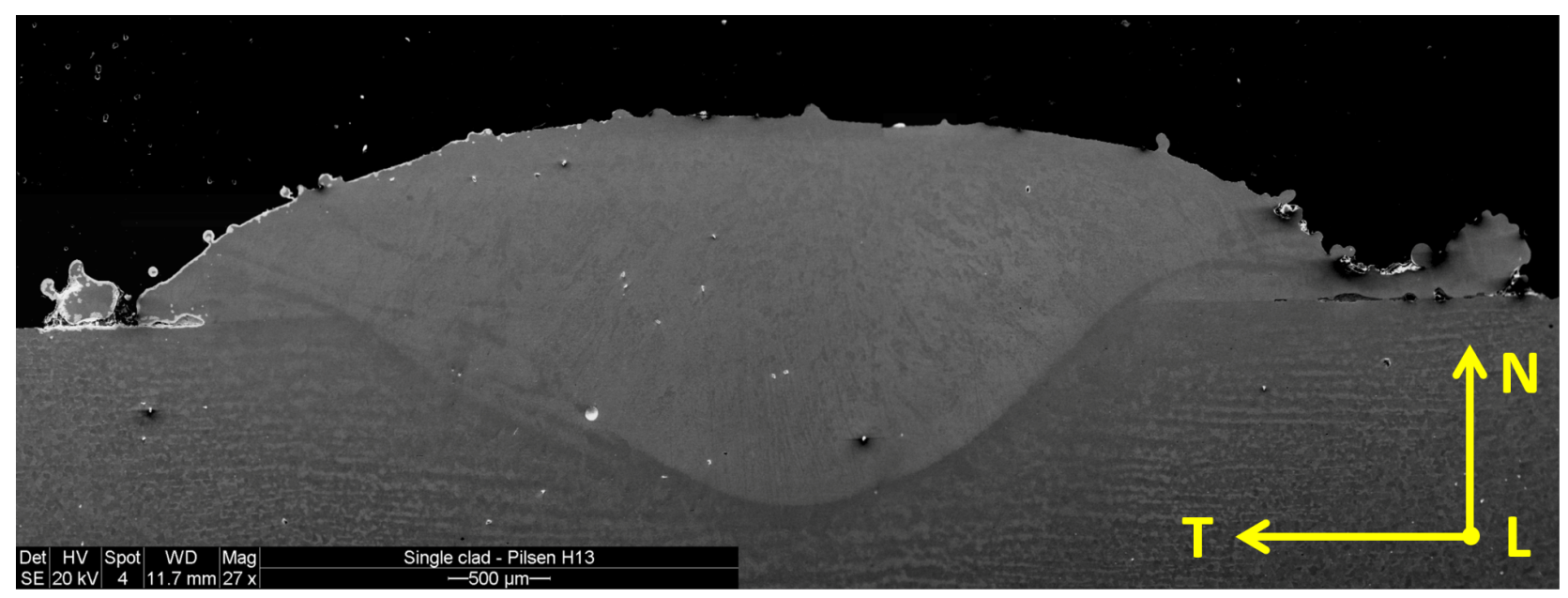

FIGURE 1. SEM image of the cross-section of the single clad AISI H13 tool steel with marked directions.

and density of dislocations. FWHM increases with the increasing microstrains and density of dislocations and decreasing crystallite size.

Hardness was measured by the instrumented indentation (nanoindentation) technique. Tests were carried out on NHT2 nanoindentation instrument (Anton Paar, Graz) with diamond Berkovich indenter. Indentation cycle consisted of loading to maximum force $500 \mathrm{mN}$ for $30 \mathrm{~s}$, holding at maximum load for $30 \mathrm{~s}$ and unloading again for $30 \mathrm{~s}$. Data were evaluated by Oliver-Pharr method [5] and the average values were computed from 3 indents for each depth under the surface of a clad. The error bar represents the standard deviation.

The OIM data for EBSD was collected using a Lyra Tescan scanning electron microscope equipped with a TSL OIM system based on Hikari camera and EDS $E D A X$ Octane detector. The accelerating voltage of $15 \mathrm{kV}$ and $50 \mathrm{~nm}$ step size of scanning were used. A grain boundary is defined in the microstructure as a boundary between two neighbouring scanning points having crystallographic misorientation larger than $5^{\circ}$. All EBSD data were analysed with TSL OIM Analysis 7.3.0 software and only data points with Confident index higher than 0.05 were used. Confident index is based on voting scheme during automated indexing of the diffraction pattern, where it is counted as a ratio of votes for the best solution minus votes for the second best solution divided by total possible number of votes from the detected Kikuchi bands. Certain crystallographic orientation receives a vote when observed angles between the three bands are the same as table values of given orientation. Confident index 0.05 corresponds on a face-centred cubic material to approx. $70 \%$ probability of correct indexing. EDS data was collected using a Philips XL 30 FEG scanning electron microscope equipped with a $E D S E D A X$ $S U T W+$ detector with accelerating voltage of $25 \mathrm{kV}$.

\section{Results AND Discussion}

Table 1 gives the range of the chemical composition of AISI H13 steel determined by ISO 4957 [6], the next row shows average chemical composition and standard deviation obtained by EDS on a cross-section of four randomly selected particles of the used powder; the bottom row shows the average chemical composition and standard deviation in four different clad crosssection areas of dimensions approx. $500 \times 250 \mathrm{\mu m}^{2}$. Table 1 shows that in the clad only chromium is on average about one weight percentage less than prescribed standard. Silicon is also slightly below the interval and vanadium is in the interval within the error. On the other hand, manganese has been observed on the contrary of $0.1 \%$ more.

Results of surface RS and FWHM obtained by XRD are shown in Table 2 and the comparison is plotted in Figure 2. The FWHM is the average value obtained from both directions with the standard deviation as the error. After first annealing a noticeable decrease in RS and FWHM was observed. Even more, in the L direction (along the clad) mild compressive RS were detected. After the second annealing there was a slight increase in RS and, above all, a significant reduction in the error. The FWHM has dropped slightly. This effect is due to a lower density of dislocation and a decrease in the value of microstrain caused by annealing.

Depth gradient of hardness is shown in Figure 3 Parameter $\mathrm{x}$ represents the distance from the surface of the clad. It can be seen from the figure that the as cladded sample exhibits a higher hardness of approximately $50 \mathrm{HV}_{0.05}$. In addition, a slower drop in hardness to the bulk values compared to annealed samples may be observed. However, there is no hardness difference between the annealed samples.

Figure 5 graphically illustrates the effect of annealing on the microstructure of the clad. An area $20 \times 20{\mu \mathrm{m}^{2}}^{2}$ in the middle of the cross-section of the clad was observed using OIM. Three differently annea- 


\begin{tabular}{lllllll}
\hline & Cr [Wt. \%] & Mo [Wt. \%] & Si [Wt. \%] & V [Wt. \%] & Mn [Wt. \%] & C [Wt. \%] \\
\hline EN ISO 4957 & $4.80-5.50$ & $1.20-1.50$ & $0.80-1.20$ & $0.85-1.15$ & $0.25-0.50$ & $0.35-0.42$ \\
\hline Powder H13 & $5.10 \pm 0.07$ & $1.79 \pm 0.08$ & $0.92 \pm 0.11$ & $1.08 \pm 0.02$ & $0.45 \pm 0.07$ & \\
\hline Clad & $3.77 \pm 0.05$ & $1.21 \pm 0.05$ & $0.72 \pm 0.01$ & $0.84 \pm 0.03$ & $0.62 \pm 0.03$ & \\
\hline
\end{tabular}

TABLE 1. Chemical composition of the steel AISI H13 according to ISO 4957 [ 6 , the powder and the clad.

\begin{tabular}{llll}
\hline & $\sigma_{\mathbf{L}}[\mathbf{M P a}]$ & $\sigma_{\mathbf{T}}[\mathbf{M P a}]$ & $\mathbf{F W H M}\left[{ }^{\circ} \mathbf{2} \theta\right]$ \\
\hline As cladded & $215 \pm 36$ & $271 \pm 48$ & $5.22 \pm 0.13$ \\
\hline Annealed $2 \mathrm{~h}, 550{ }^{\circ} \mathrm{C}$ & $-63 \pm 49$ & $54 \pm 30$ & $4.37 \pm 0.03$ \\
\hline Annealed $2+2 \mathrm{~h}, 550{ }^{\circ} \mathrm{C}$ & $-21 \pm 16$ & $144 \pm 9$ & $4.35 \pm 0.02$ \\
\hline
\end{tabular}

TABLE 2. Results of surface RS and FWHM of the clad.

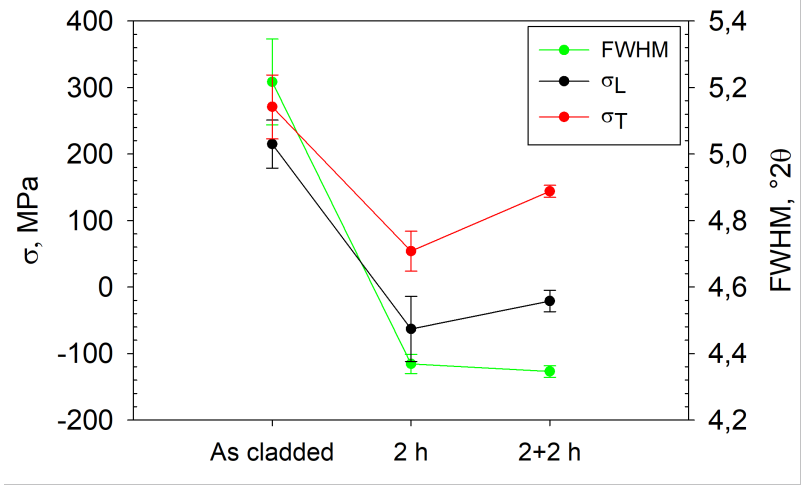

Figure 2. Surface RS and FWHM of the clad.

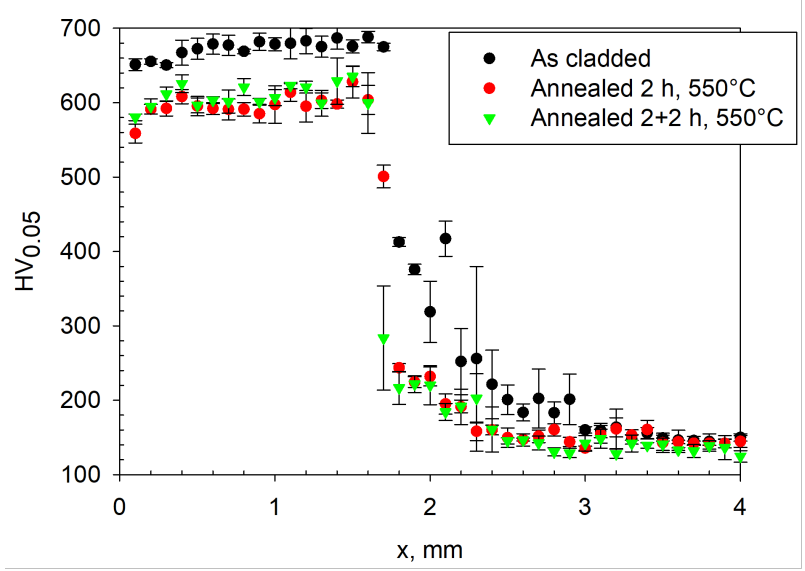

Figure 3. Depth gradient of hardness, where $\mathrm{x}$ is distance from the surface of the clad.

led samples were used, so the measured area was not the same. As shown also in Figure 4, it can be stated that the annealing time increases the proportion of carbides and decreases the austenite fraction. This effect is well known and not surprising when diffusion is facilitated by higher temperature. However, the weight percentage of the carbides that were indexed during the measurement (see Figure 4) is inconsistent

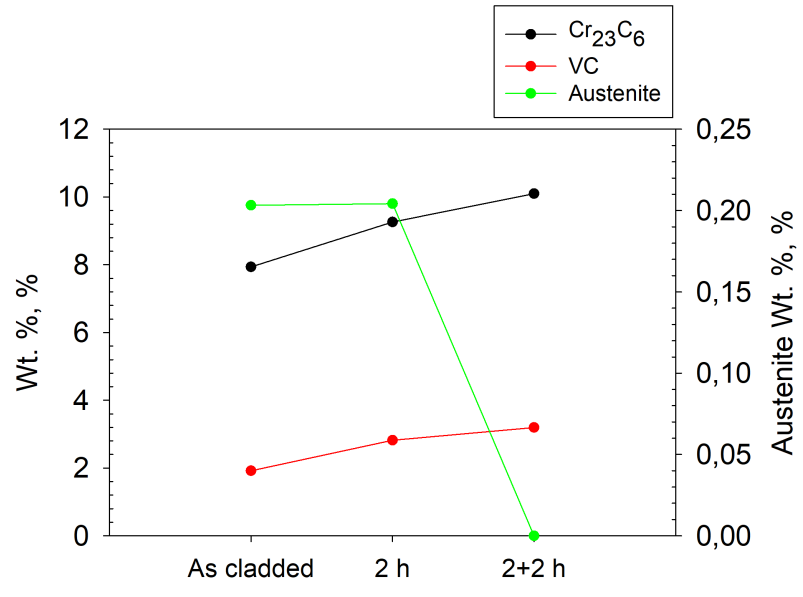

FIGURE 4. Effect of annealing on the phase content of the clad.

with Table 1 Carbides have been indexed three times more than the steel composition obtained by EDS analysis showed. Inverse pole figures of ferrite in the selected area before and after annealing are shown in Figure 6, wherein individual colours correspond to the normal vectors of crystallographic planes that are parallel to the normal vector of the cross-section of the sample. After cladding, the martensitic structure could be observed and vice versa after annealing. However, a slight rounding of corners of martensitic laths can be found after annealing for $2+2$ hours.

\section{Conclusions}

Laser deposition of the AISI H13 tool steel showed a great application potential. By annealing, residual stresses have dropped, which could have a beneficial effect on the component life time, as the compressive stresses delay crack initialization and also slow its propagation [7]. The difference between phase composition detected by EDS and EBSD has not yet been accurately explained and understood, so further measurements and adjustments of the indexing parameters will be needed. Nevertheless, based on these results, 

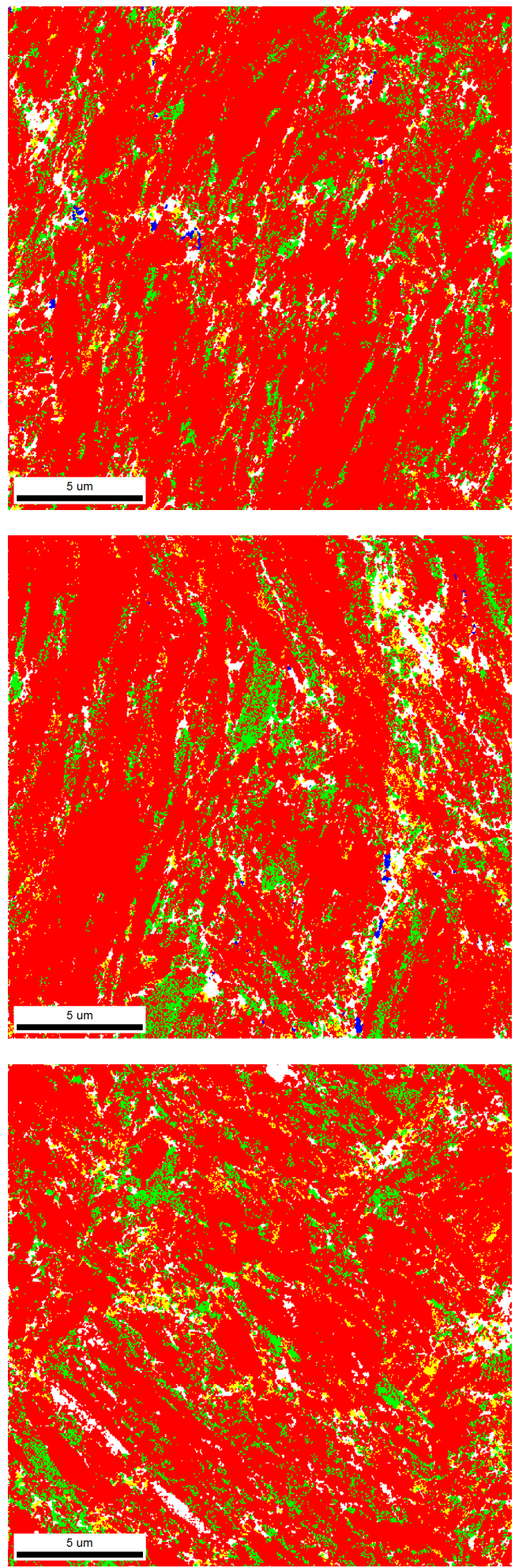

FiguRE 5. Effect of annealing on the phase composition of the clad where ferrite is red, $\mathrm{Cr}_{23} \mathrm{C}_{6}$ green, $\mathrm{VC}$ yellow and austenite blue (upper as cladded, middle after $550{ }^{\circ} \mathrm{C}$ annealing for $2 \mathrm{~h}$, bottom after $550{ }^{\circ} \mathrm{C}$ annealing for $2+2 \mathrm{~h}$ ).

annealing is not needed after cladding. However, verification on real dies and also further measurements are required, in particular wear resistance testing.
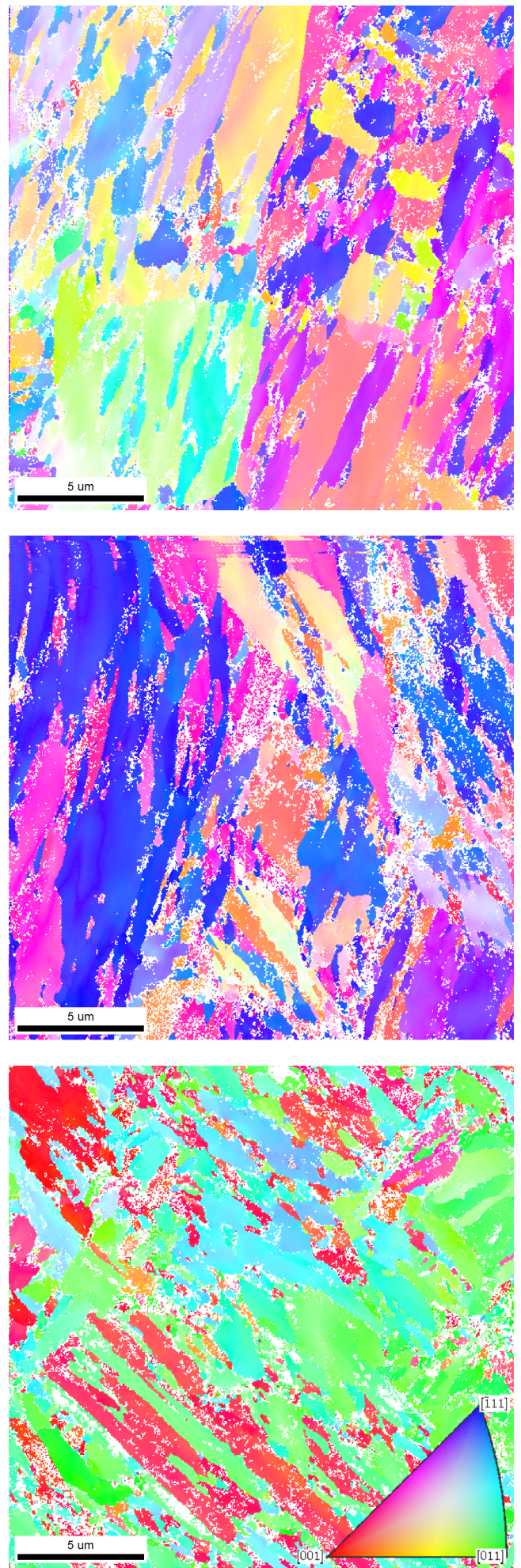

FiguRE 6. Effect of annealing on the microstructure of the ferrite of the clad (upper as cladded, middle after $550{ }^{\circ} \mathrm{C}$ annealing for $2 \mathrm{~h}$, bottom after $550{ }^{\circ} \mathrm{C}$ annealing for $2+2 \mathrm{~h}$ ).

\section{ACKNOWLEDGEMENTS}

Measurements were supported by the project TH02010664 of the Technology Agency of the Czech Republic and by University of Groningen. This work was supported by the Student Grant Competition CTU in Prague grant No. SGS16/245/OHK4/3T/14. 


\section{REFERENCES}

[1] G. Telasang, J. D. Majumdar, N. Wasekar, et al. Microstructure and mechanical properties of laser clad and post-cladding tempered AISI H13 tool steel. Metallurgical and Materials Transactions A 46:2309-2321, 2015. DOI:10.1007/s11661-015-2757-z

[2] M. Vedani, B. Previtali, G. M. Vimercati, et al. Problems in laser repair-welding a surface-treated tool steel. Surface $\mathscr{E}$ Coatings Technology 201(8):4518-4525, 2007. DOI:10.1016/j.surfcoat.2006.09.051

[3] J. Chen, S.-H. Wang, L. Xue. On the development of microstructures and residual stresses during laser cladding and post-heat treatments. Journal of Materials Science 47(2):779-792, 2012. DOI:10.1007/s10853-011-5854-4
[4] V. Hauk, E. Macherauch. A useful guide for X-ray stress evaluation (XSE). Advanced in X-ray Analysis 27:81-99, 1989.

[5] W. Oliver, G. M. Pharr. An improved technique for determining hardness and elastic modulus using load and displacement sensing indentation experiments. Journal of Materials Research 7(6):1564-1583, 1992. DOI:10.1557/JMR.1992.1564.

[6] EN ISO 4957:1999 Tool steels. Standard, British Standards Institution, 1999.

[7] G. E. Totten, M. Howes, T. Inoue, I. Books24x7. Handbook of residual stress and deformation of steel. ASM International, Materials Park, 2002. DOI:10.1361/hrsd2002p027. 